\title{
Doenças crônicas não transmissíveis, absenteísmo escolar e boas práticas em Pedagogia Hospitalar
}

\author{
Léa Chuster Albertoni ${ }^{1}$
}

\begin{abstract}
RESUMO
O presente artigo tem por objetivo analisar a relação entre as Doenças Crônicas Não Transmissíveis e o processo de escolarização sob a ótica da multiplicidade de fatores que compõem esse tema. As doenças crônicas e as de longa duração constituem uma das vertentes preocupantes na vida de uma parcela bastante significativa de crianças e adolescentes. Portanto, é necessário aproximar educação e saúde, compreender as necessidades advindas das situações crônicas física e mental, identificar as condições de risco e estimular a permanência e a continuidade do processo de desenvolvimento e de escolarização desses alunos. A permanência e a (re)integração escolar dessa população serão aqui abordadas segundo o conceito de Boas Práticas em Pedagogia Hospitalar. Salienta-se, igualmente, neste artigo a importância da formação docente como elemento essencial para o redimensionamento das ações pedagógicas e educacionais na busca de melhores condições de vida dos alunos que vivenciam situações de enfermidade crônica.
\end{abstract}

PALAVRAS-CHAVE: Pedagogia Hospitalar. Absenteísmo. Doenças Crônicas Não Transmissíveis.

Chronic Noncommunicable Diseases (NCD), School Absenteeism and Good Practices in Hospital Pedagogy

\begin{abstract}
The purpose of this article aims to analyze the relation between Chronic Noncommunicable Diseases and the schooling process from the perspective of the multiplicity of factors involving this theme. Chronic and
\end{abstract}

\footnotetext{
${ }^{1}$ Doutora em Ciências pela Escola Paulista de Medicina - Universidade Federal de São Paulo, São Paulo, SP, Brasil. Orcid: https://orcid.org/0000-0003-3728-9103.E-mail: albertonilc@uol.com.br.
} 
long-term diseases are one of the aspects of concern in the lives of a significant portion of children and adolescents. Therefore, bringing education and health closer is a must, as well as understanding the needs arising from chronic physical and mental conditions, identifying risk conditions and encouraging the permanence and continuity of the development and schooling process of such students. The permanence and school (re)integration of this population will be addressed here according to the concept of Good Practices in Hospital Pedagogy. This articles also emphasizes the importance of teacher training as an essential element for the resizing of pedagogical and educational actions in the search for better living conditions of students who experience situations of chronic illness.

KEYWORDS: Hospital Pedagogy. School Absenteeism. Chronic Noncommunicable Diseases.

\section{Enfermedades crónicas no transmisibles, absentismo escolar y buenas prácticas en la pedagogía hospitalaria.}

\section{RESUMEN}

Este artículo tiene como objetivo analizar la relación entre las Enfermedades Crónicas No Transmisibles y el proceso de escolarización desde la perspectiva de la multiplicidad de factores que componen esta temática. Las enfermedades crónicas y de larga duración son uno de los aspectos que preocupan en la vida de una parte muy importante de la niñez y la adolescencia. Por lo tanto, es necesario acercar la educación y la salud, comprender las necesidades que surgen de las situaciones crónicas físicas y mentales, identificar las condiciones de riesgo y fomentar la permanencia y continuidad del proceso de desarrollo y escolarización de estos estudiantes. La permanencia y reintegración escolar de esta población se abordará aquí según el concepto de Buenas Prácticas en Pedagogía Hospitalaria. También se enfatiza en este artículo la importancia de la formación del profesorado como elemento esencial para el redimensionamiento de las acciones pedagógicas y educativas en la búsqueda de mejores condiciones de vida para los estudiantes que viven situaciones de enfermedad crónica.

PALABRAS-CLAVE: Pedagogía hospitalaria. Absentismo.

Enfermedades crónicas no transmisibles. 


\section{$* * *$}

\section{Introdução}

A relevância de se abordar o tema sobre as condições crônicas de saúde, relacionando-o ao absenteísmo escolar, diz respeito ao conceito de educação integral e implica a necessidade de explorar as contribuições da área da educação tanto no enfrentamento de Doenças Crônicas (DCs), quanto na busca de oportunidades para o desenvolvimento global e para a qualidade de vida ao longo do ciclo vital. Trata-se de uma lógica de cuidados mais condizentes com os avanços na área da Pediatria, os quais rumam em direção a uma expectativa de vida longeva.

A melhora das condições crônicas na infância, devido aos avanços científicos e tecnológicos, faz configurar essa enfermidade como uma tendência epidemiológica (STEIN2, 2011 apud DUARTE, et al., 2015, p. 1009-1017). Gerenciar a doença como suporte mediador da vida e do desenvolvimento de crianças e adolescentes reforça a importância de interagir com o meio, bem como oportuniza a expressão de afetos, desejos, medos e esperanças. Considerando as dimensões física, emocional e social, a amplitude do tema, associado ao trabalho em rede, favorece o pleno desenvolvimento de potencialidades e competências. Além disso, a ação docente, quando caracterizada multiprofissional e interdisciplinarmente, integra saberes e promove a construção de uma prática a partir da conjunção de várias áreas do conhecimento.

Segundo a definição da Organização Mundial de Saúde (OMS) (OMS, 2003), as condições crônicas de saúde caracterizam-se pela necessidade de tratamento contínuo e duradouro, demandando cuidados permanentes. As limitações decorrentes podem ser de base biológica, psicológica e cognitiva, destacando-se suas respectivas repercussões, como limitações de determinadas funções, restrições no desempenho de papéis sociais,

\footnotetext{
${ }^{2}$ STEIN R. E. The 1990s: a decade of change in understanding children with ongoing conditions. Arch Pediatr Adolesc Med, v. 165, n. 10, p. 880-883, Oct. 2011.
} 
dependência de medicamentos, alimentação especial, uso de dispositivo tecnológico e cuidados assistenciais em serviços de saúde (STEIN³, 2011 apud DUARTE et al., 2015, p. 1009-1017).

Rolland4 (1995 apud VIEIRA; LIMA, 2002, p. 552-560) traça um paralelo entre as fases da DC e as etapas do desenvolvimento humano, relacionando-as de forma didática ao processo de aprendizagem das tarefas básicas para seu enfrentamento. Assim sendo, destacam-se aqui duas delas: a crise e a crônica. A fase crise assemelha-se ao período da infância e demanda aprendizagem para o convívio com a enfermidade. Viver e conviver com a situação crônica não se restringem à pessoa, exigindo adaptações de todos os que estão no entorno: família, escola, amigos e comunidade. Trata-se de construir e utilizar estratégias para minimizar os efeitos da doença e do adoecer, sempre levando em conta a gravidade, a complexidade e a singularidade de cada um dos elementos que compõem o quadro clínico. Por sua vez, a fase crônica clama por autonomia e construção de uma estrutura de vida possível. Corroborando esse estudo, Woods ${ }^{5}$ et al. (2020, apud VIEIRA; LIMA, 2002, p. 552-560) acrescentam às fases citadas uma terceira etapa, a terminal, considerada a de maior sofrimento uma vez que a morte se torna mais próxima.

Portanto, frente aos desafios, é preciso repensar o papel da educação sob a perspectiva do oferecimento de ações que satisfaçam as demandas ligadas aos períodos de tratamento, recuperação, prevenção de agravos e promoção do desenvolvimento global do aluno. Para isso, a articulação de conhecimentos teóricos e práticos entre saúde e educação, segundo os aspectos individuais e coletivos, concretiza a integralidade e colabora para que crianças, adolescentes e suas famílias tenham melhor qualidade de vida.

Se, por um lado, os estudos mostram a importância da interação social, familiar e escolar dos que vivem a condição crônica de saúde, por outro, essas análises chamam a atenção aos cuidados necessários para a

\footnotetext{
${ }^{3}$ STEIN. op. cit.

${ }^{4}$ ROLLAND, J. S. Doença crônica e o ciclo de vida familiar. In: CARTER, S.; GOLDRINLE, M. As mudanças no ciclo de vida familiar. Porto Alegre (RS): Artes Médicas; 1995. p. 372-392.

${ }^{5}$ WOODS NF, YATES BC, PRIMONO J. Supporting families during chronic illness. Image: J Nurs Scholarship, 1989, v. 21, n. 1, p. 46-50, 1989.
} 
manutenção das respectivas condições de vida. Medicamentos, dietas especiais, ventilação mecânica, nutrição parenteral, oxigenoterapia ou implantação de cateteres, quando necessário, são elementos igualmente fundamentais tanto para a rotina diária, como em situações de exacerbação das enfermidades. Doenças Crônicas Não Transmissíveis (DCNTs), como pulmonares obstrutivas crônicas (bronquite crónica e enfisema pulmonar, por exemplo), cardiovasculares (hipertensão, insuficiência cardíaca), AVC (doença vascular periférica e outras), diabetes, câncer, renais crônicas, neuropsiquiátricas (como a depressão,), apresentam um quadro complexo de agravos e instabilidades, os quais geram repercussões no desenvolvimento global e na qualidade de vida (OMS, 2003; BEN SHLOMO; KUH6, 2002 apud MOREIRA; GOMES; SÁ, 2014, p. 2083-2094).

As condições de saúde tanto crônicas quanto agudas exigem respostas sociais proativas, episódicas ou contínuas, que, por sua vez, podem demandar ações fragmentadas ou integradas, de acordo com a tipologia, e orientadas por conceitos-chave, como tempo de duração (breve ou longo) e forma de enfrentamento. Com base nas informações coletadas pelas equipes compostas por profissionais de saúde e educação, será possível e necessário desenvolver um trabalho conjunto a fim de alcançar um objetivo comum, traçar ações de acolhimento e promover o comportamento resiliente.

O desconhecimento e a falta de informações sobre a situação crônica de saúde pela equipe escolar podem incorrer no risco de interpretar essa condição como sendo aguda e, assim, criar a expectativa de resultados imediatos (NESCON, Organização Pan-Americana de Saúde, 2012). Esses fatores facilmente podem desencadear ações e procedimentos inclusivos, favorecer 0 manejo positivo da doença e motivar a manutenção do vínculo do aluno e da família com a escola ou criar uma situação desfavorável, colocando crianças e adolescentes em posição vulnerável e alvo de bullying, distanciando-os dos demais colegas, bem como do convívio social e escolar.

\footnotetext{
${ }^{6}$ BEN SHLOMO, Y.; KUH, D. A life course approach to chronic disease epidemiology: conceptual models, empirical challenges, and interdisciplinary perspectives. Int J Epidemiol, v. 31, n. 2, p. 285-293, abr. 2002.
} 
Observa-se, então, que a complexidade do tema é proporcional à sua importância. Questões como reinserção escolar após hospitalização, manutenção do vínculo escolar como fator determinante para a saúde física e mental dos alunos em situação de enfermidade, formação de redes sociais de apoio, criação de comunidades acolhedoras e estímulo ao comportamento resiliente como resposta possível à adversidade vivida pelas DCNTs encontram-se intimamente ligadas aos pressupostos da Pedagogia Hospitalar. Sem a intenção de esgotar um campo tão amplo, o que se pretende neste artigo é, sim, alertar para uma realidade ainda pouco explorada em nosso país. Trata-se de um campo para novas pesquisas, sobretudo na área da formação de professores com foco para concepções e práticas inclusivas, com base nas repercussões das DCNTs, especialmente para crianças e jovens que vivem a exclusão socioeducacional (SALDANHA; SIMÕES, 2013; ALBERTONI, 2014).

\section{As representações do adoecer}

Um dos estudos mais significativos sobre a forma pela qual pessoas leigas registram a concepção de saúde e de doença foi realizado por Claudine Herzlich (1973) na França. Nele, cerca de 800 pessoas foram entrevistadas. Os dados conclusivos dividem-se em três categorias: a) a doença como destruidora: quando suas repercussões interferem nos desempenhos escolar, profissional e familiar. Sob essa perspectiva, a doença promove uma postura dependente e gera uma sensação de desvalia. Assim sendo, vive-se uma ambiguidade: o desejo de controlar a doença, negando sua existência e, por vezes, os sentimentos de impotência e indisponibilidade para lutar contra a mesma; b) a doença como libertadora de responsabilidades e pressões frente ao desempenho de papéis; e c) a doença como desafio, fato que desperta energia, empenho e concentração rumo à recuperação ao aproximar mente e corpo.

Segundo a autora, raros foram os participantes que se detiveram em somente uma das três categorias. De maneira geral, os relatos mostraram que todas elas fazem parte dos sentimentos do adoecer. Portanto, perceber o corpo 
como um mistério e sentir a estranheza de sintomas nos períodos em que a doença se apresenta de forma exacerbada potencializam o medo, geram situações de estresse e até mesmo dificultam a adesão ao tratamento.

Sem compreender exatamente o que se passa ao adoecer, crianças e adolescentes percebem que algo importante ocorre em seus corpos, podendo ser sentido pela dor e pelas expectativas em relação aos exames frequentemente realizados por médicos e pelas equipes da saúde. De um lado, estão os profissionais instrumentalizados por aparelhos, como estetoscópios, medidores de pressão arterial, entre tantos menos conhecidos, e, de outro, estão as crianças e adolescentes impossibilitados de realizar suas atividades rotineiras, como brincar, correr e participar das aulas presencialmente.

Comumente simultâneas, surgem agressões verbais, físicas, sociais e psicológicas, trazendo aos que já vivem a dor e o desconforto das enfermidades as intimidações que expõem, afastam e ridicularizam essa população, causando sofrimento e agravamento do estado físico, já tão vulnerável pela própria doença.

\section{Doenças Crônicas}

As Doenças Crônicas (DCs) são as principais causas de morte no mundo. A elas foram atribuídos 35 milhões de óbitos em 2005, quase $60 \%$ da mortalidade mundial, o que representa $45,9 \%$ da carga global das enfermidades. Há décadas, a OMS (2003) fez uma estimativa que hoje se confirma: em 2020, as DCs deverão responder por $73 \%$ de óbitos, ou seja, $60 \%$ da carga de doenças em geral. Também, nesse mesmo estudo, destacou-se uma importante redução das Doenças Crônicas Transmissíveis (DCTs) em comparação ao aumento das Doenças Crônicas Não Transmissíveis DCNTs.

Corroborando essa questão, um estudo realizado por Barros et al. (2006) chama a atenção para o fato de que, no século XXI, um apanhado de fatores demográficos, econômicos e sociais devem ser considerados significativos para dar consistência aos dados pesquisados. Levar em conta as demais informações determinantes, como sexo, idade, etnia, escolaridade, macrorregião de 
residência, situação urbana ou rural do domicílio e escolaridade, possibilita traçar o padrão populacional com clareza e precisar as causas não só físicas, mas também socioculturais que dão origem às DCs em geral.

Aceitar o adoecer de crianças ou jovens é uma experiência dolorosa para a família e para aqueles que os cercam. O quadro ainda se agrava quando essas doenças apresentam um prognóstico fechado ou uma baixa expectativa de vida. A falta de controle frente à evolução das enfermidades causa impotência e ansiedade sobre as perspectivas futuras.

Isso posto, aflora-se a empatia para compreender que o cuidar profissional nas áreas da saúde e da educação deverá ser sensível, menos tecnicista e abrangente para se chegar aos alunos da educação e pacientes da saúde com um olhar compreensível e panorâmico para muito além da doença. $\mathrm{O}$ século XXI, desde seu início, anuncia grandes desafios para os campos da saúde e da educação. Nesse contexto, a escola deve se propor a ir além do desenvolvimento das habilidades cognitivas e também se dedicar ao acolhimento das singularidades de seus alunos em situação crônica de saúde nos períodos pré, durante e pós-hospitalização.

\section{Doenças Crônicas Não Transmissíveis}

No contexto das doenças crônicas, as DCNTs constituem um grupo bastante expressivo. Atingem, especialmente, as populações mais vulneráveis, como as de baixa renda e escolaridade, estão em ascensão e merecem destaque, pois trazem prejuízos para a vida de uma parcela significativa da população tanto adulta quanto infantojuvenil.

Por sua vez, a vida escolar desses alunos fica muito comprometida pela dificuldade de manter a constante presença física em sala de aula devido aos períodos de agravamento da doença, de convalescença e até mesmo do tempo dedicado aos tratamentos necessários. Segundo a OMS, essa população representa um problema de saúde de grande magnitude. A consulta às séries históricas de estatísticas sobre mortalidades, disponíveis para as capitais dos 
estados brasileiros, indica que a proporção de mortes por DCNTs aumentou três vezes mais entre 1930 e 2006 (MALTA et al., 2014).

A revisão bibliográfica realizada por Moreira; Gomes e Sá, (2014) sobre a natureza das publicações e dos artigos indexados nas bases de dados, excluindo teses e livros a respeito das DCs em crianças e jovens, entre 2003 e 2011, traz uma contribuição importante para que se possa refletir sobre a relação entre as características das DCs e seu impacto socioemocional em crianças e adolescentes.

Em âmbito nacional, a política intersetorial das áreas de educação e saúde deve ser observada mediante o universo da corresponsabilidade social de ambos os setores na busca de qualidade do atendimento integral à saúde do escolar. Assim, vê-se resguardado o direito à diferença na igualdade de oportunidades mediante uma educação que prima pela equidade, propiciando qualidade sob a perspectiva da educação inclusiva.

\section{Limite e continuidade do processo de escolarização}

Internações hospitalares e longos tratamentos de saúde podem ser interpretados como fatores limitantes para a continuidade dos processos de desenvolvimento e escolarização, legalmente instituído pela Constituição Federal Brasileira (BRASIL, 1988). Nessa direção, como é de conhecimento, nas circunstâncias de internação, nos atendimentos em hospital-dia ou hospital-semana ou, ainda, nos serviços de atenção integral à saúde mental, o acompanhamento pedagógico-educacional faz-se presente em salas e leitos e são denominados Classes Hospitalares (BRASIL, 2002). O documento que discorre sobre orientações e estratégias para a implantação e o funcionamento das Classes Hospitalares ressalta a função dessa modalidade educacional na promoção do “... ingresso, retorno ou adequada integração ao seu grupo escolar correspondente, como parte do direito de atenção integral'.

Sendo assim, as Classes Hospitalares são responsáveis pela mediação entre estudantes em contextos de tratamentos de saúde, suas respectivas 
escolas de origem e equipes da saúde e seus familiares/responsáveis. Segundo essa perspectiva, o paradigma que embasa os processos de ensino e aprendizagem coloca o aluno como foco central dessa interação.

Oliveira et al. (2009) escrevem a respeito das possíveis articulações entre a prática pedagógica nas Classes Hospitalares e a escola regular, apontando como um dos entraves o desconhecimento de pais e familiares sobre essa modalidade de educação especial, não obstante o fato de várias políticas públicas afirmativas sobre inclusão terem sido elaboradas, contemplando-as.

Como forma de corroborar a importância na manutenção do vínculo dos alunos hospitalizados e de suas famílias com as respectivas escolas de origem, recorreu-se a um estudo sobre a percepção que as famílias de crianças hospitalizadas com doenças crônicas têm sobre o afastamento escolar. Os resultados mostram o reconhecimento do trabalho realizado nas Classes Hospitalares para a manutenção da qualidade de vida. Todavia, os familiares entrevistados insistem na programação de ações pedagógicas sistematizadas, relacionando-as ao apoio para melhor desempenho escolar e atenção na construção de um caminho de estabilidade e de esperança (HOLANDA; COLLET, 2011).

Todavia avaliar e organizar os atendimentos pedagógicos e psicoeducacionais nas Classes Hospitalares pressupõem conceber que estes não se restringem apenas às práticas escolares com enfoque conteudista. Muito pelo contrário, a atenção aos alunos em situação de enfermidade deve ser pautada pela perspectiva multifatorial. Assim considerada, a ação do docente na prática da Pedagogia Hospitalar agrega um conjunto de fatores, tornando a atividade profissional nessa área uma tarefa multifacetada, complexa e relacional. Ao mesmo tempo em que apresentam um perfil voltado à subjetivação e à socialização, os atendimentos estimulam a autonomia e a interseção social dos estudantes enfermos. Para tanto, avaliam as necessidades individuais, estimulam a apropriação significativa dos saberes e buscam a transformação das adversidades em novas aprendizagens. 
Regida por normas e princípios que compõem a Pedagogia Geral, a Pedagogia Hospitalar constitui um campo de atuação que atende às necessidades particulares de alunos enfermos, acompanhando-os o quanto possível nas diferentes etapas da vida, sem deixar de considerar os seguintes contextos de pertencimento: escola, família e comunidade (LIZASOÁIN; POLAINO-LORENTE, 2007; 1992). Mediante o conceito de Boas Práticas, a Pedagogia Hospitalar também busca difundir ações inovadoras e criativas, sustentáveis a seu entorno.

\section{Escola: caminho para (trans)formar}

Em razão do crescente número de crianças e jovens com doenças e/ou condições crônicas de saúde, há cuidados que devem ser garantidos pela escola regular escolhida, a fim de tornar possível a vinculação presencial ou a distância desse alunado. Um dos pontos fundamentais está centrado na interação social e na comunicação com os demais alunos e professores, seja de maneira presencial, seja de maneira virtual.

A vulnerabilidade tanto física quanto emocional desses alunos e a dificuldade de inserção nos grupos por problemas relacionados à autoimagem, à tristeza e à depressão exigem do professor e de toda a equipe um trabalho conjunto: a integração de vários atores sociais envolvidos, como a família dos alunos e a comunidade em que estão inseridos. Isso ocorre porque avaliar a doença como único fator responsável pelas restrições e obstáculos no desenvolvimento e no acompanhamento escolar pode dar margem a diagnósticos parciais, discriminatórios e classificatórios. Em nome da doença, as ações para integrar ou reintegrar alunos que vivem a situação das DCNTs facilmente se restringem ao pré-conhecimento dos alunos como um todo e ao pré-julgamento, fato que limita oportunidades e esperanças no desenvolvimento de possibilidades, competências e habilidades (JERUSALINSKY; LUGON, 2016). 
Se a situação clínica dos alunos implica cuidados especiais na escola, levar ao conhecimento dos responsáveis as condições necessárias para sua permanência é fato consumado para o envolvimento e estabelecimento de uma parceria corresponsável. $\mathrm{O}$ ato de providenciar as condutas necessárias para a permanência de estudantes na escola colabora para ações de acolhimento com segurança. Exemplos dessas situações são os cuidados a serem tomados em relação aos episódios de hipoglicemia e coma em diabéticos, à dispneia em pacientes asmáticos e às convulsões em epiléticos. Alertar a escola sobre as medicações em uso e as atividades contraindicadas faz ventilar informações que devem ser evidenciadas com o consentimento dos alunos e resguardadas com base nos princípios da ética profissional (NOGUEIRA, 2016).

Todavia quando a escola não se alinha à perspectiva de respeito às singularidades de seus alunos e, sim, à utopia do modelo de aluno idealizado, acaba por minimizar ou superestimar as repercussões do adoecer, justificando as questões do absenteísmo e fracasso escolar como meras dificuldades individuais do aluno. Em tais procedimentos, o professor perde a oportunidade de construir seu papel como elo entre o conhecimento e a formação de cidadãos mais críticos e conhecedores de seus direitos e deveres.

Se as DCs representam um desafio à rotina escolar, a literatura aponta para o fato de que geralmente as escolas têm se esquivado de temas que levam seus professores a rever posturas, a recriar práticas e a entender as novas possibilidades educativas trazidas pela inclusão.

Segundo Cury (2008), situações de desigualdade, disparidade e discriminação produzidas fora da escola acabam por reforçar situações de precariedade no interior dela. Assim, a educação inclusiva, sob o aspecto de dispositivo, pode se constituir em estratégia de (trans)formação, favorecendo a invenção de outros modos de funcionamento institucional, ou seja, de uma outra estética para a existência da própria escola.

No dizer de Mantoan (2012), as questões que refreiam a ressignificação e tratam do papel do professor, de seus aprendizados e de sua formação profissional segundo os moldes da hegemonia e da primazia dos conteúdos 
acadêmicos precisam ser debatidas. Nessa linha, a perspectiva de trazer à tona as singularidades dos alunos em situação de enfermidade na escola seguramente está de acordo com pressupostos teóricos e práticos considerados alavancadores da formação do novo profissional em um mundo globalmente informatizado, somando novos desafios ao planejamento das ações educacionais.

\section{Absenteísmo, abandono e evasão escolar}

A participação do aluno em condição crônica de saúde na escola diz respeito à construção de estratégias segundo ações de corresponsabilidade social em busca da qualidade de serviços que assegurem os direitos legais em ambas as áreas. Todavia ultrapassar barreiras e programar estratégias rumo à superação das dificuldades desses estudantes demandam uma rede de sustentação para implementar o processo educacional inclusivo.

Um estudo feito por Enumo, Ferrão e Ribeiro (2006) concretiza o fato de que o desempenho nas atividades escolares e as relações familiares têm influência recíproca e significativa no processo de aprendizagem e de escolarização. Sob essa perspectiva, ao grupo familiar cumpre o papel de agente ativo e diretamente participante no tratamento da saúde e no desempenho socioemocional de seus membros, especialmente nas fases iniciais do ciclo de vida. A partir de um olhar sistêmico e comunicativo sobre a convivência dos membros que integram uma família, é possível afirmar que a doença desestabiliza a dinâmica familiar, abalando os padrões de funcionamento já instituídos até que se estabeleça uma nova forma de convívio possível. De acordo com essa concepção, o professor pode colaborar ao conhecer a família dos alunos que vivem essa situação de conflito, compreender suas necessidades e até mesmo estabelecer uma parceria com bons resultados

Quantificar casos de evasão e abandono escolar é tarefa difícil e parte da dificuldade está em considerar a natureza e os princípios de suas respectivas origens. Todavia, entre os fatores que determinam a evasão, certamente o fracasso escolar pode ser considerado um dos elementos determinantes. 
Segundo Charlot (2000), o fracasso escolar é produto de vários fatores, entre eles o processo de ensino, a falta de igualdade nas oportunidades oferecidas, a administração de crises pessoais e perspectivas de vida. Por conseguinte, dificuldades de aprendizagem e fracasso escolar são questões complexas e não se limitam unicamente à condição crônica, embora as repercussões advindas do estado de saúde no processo de ensino e aprendizagem não possam ser desconsideradas.

Sendo assim, o incentivo do professor e dos colegas pode ser determinante para que o aluno se sinta confiante em estar presente na escola. O acompanhamento em todos os momentos pode dotar de sentido e ressignificar a adversidade. É parte do acolhimento conhecer a história pregressa dos alunos, saber dos motivos que os conduziram ao ingresso na escola escolhida, desvelar seu percurso e as causas singulares que os levaram a permanecer ou a desistir de frequentá-la (SILVA FILHO; ARAÚJO, 2011).

Por sua vez, o absenteísmo escolar, terminologia ainda pouco utilizada na área da educação, vem se tornando cada vez mais frequente na revisão da literatura. Quando na área administrativa, refere-se à análise da rotatividade de funcionários e aos possíveis problemas em um determinado setor da empresa e abre espaço para compreender ausências no trabalho quando o motivo interveniente é a doença (SALDARRÍAGA; MARTÍNEZ, 2007). Quando na área da educação, o absenteísmo está relacionado às faltas escolares. Faz-se, então, necessário compreender o cenário em que o absenteísmo ocorre e construir para essa prática um significado. Assim será possível antever ações, estabelecer parcerias intra e extramuros da escola e resgatar a participação de estudantes, tendo como ponto de partida sua própria história.

Nessa direção, Gilly (2001 apud VASCONCELLOS; MATTOS, 2011, pp. 271-296), em Análise da relação entre o perfil psicossocial do aluno e o abandono escolar, do Projeto Integrar para Educar, da cidade de Faro ${ }^{8}$, em Portugal, faz uma

\footnotetext{
${ }^{7}$ GILLY, M. As Representações Sociais no campo da Educação. In: JODELET, D. (Org.). As Representações Sociais. Tradução de Lilian Ulup. Rio de Janeiro: EDUERJ, 2001.

${ }^{8}$ Câmara Municipal de Faro, Divisão de Acção Social, Análise da relação entre o perfil psicossocial do aluno e o abandono escolar. Projecto "Integrar para Educar"- Programa Ser Criança. Ministério do Trabalho e Solidariedade Social, da Câmara Municipal de Faro. Portugal, 2007.
} 
análise sobre o absenteísmo, relacionando-o às experiências vividas em dois contextos do desenvolvimento humano: o da família e o da escola, considerando estes como fatores intrínsecos e extrínsecos. Os intrínsecos são experiências educacionais referentes aos processos de vida de cada estudante, e as ações intervenientes são consideradas fatores ligados à saúde física, ao equilíbrio emocional, ao grau de integração com escola, à motivação pessoal para a aprendizagem e às dificuldades de relacionamento com seus pares e com o corpo docente. Fatores extrínsecos referem-se à família e à escola. Enquanto família, destacam-se o grau de letramento dos progenitores, a importância que o sistema familiar atribui à escolaridade e aos projetos de vida futuros, bem como os níveis econômicos e socioculturais. Enquanto escola, destacam-se acolhimento, respeito às diferenças, organização administrativa, coordenação, metodologia, qualidade do clima de convivência, entre outros (GILLY9, 2001 apud FARO, 2007). Concluise, portanto, que os consecutivos insucessos na escola devem ser atribuídos a múltiplos fatores expressivos na elucidação da evasão escolar.

\section{Pedagogia Hospitalar, Formação Profissional e Boas Práticas}

A Pedagogia Hospitalar, um modo singular de atenção pedagógica e educacional, também proporciona recursos para uma visão sistêmica sobre os processos de ensino e aprendizagem, com o objetivo de dar respostas às necessidades biopsicossociais de pessoas com enfermidades em ambulatórios, hospitais, domicílios e escolas. Segundo essa perspectiva, a educação se efetiva de forma dinâmica, integral e multifatorial e se manifesta também na promoção da saúde, permitindo compreender a enfermidade e a hospitalização como inquestionáveis oportunidades para a evolução de habilidades socioemocionais, sendo facilitadora no caminho para o desenvolvimento das estratégias e do autocuidado pessoal (MOLINA, VIOLANT e LIZASOÁIN, 2013). Disso resulta sua extensão em

\footnotetext{
${ }^{9}$ GILLY, op. cit.
} 
diferentes contextos para os alunos em situação de enfermidade em diferentes etapas da vida. Igualmente, a Pedagogia Hospitalar mantém um forte vínculo com a Pedagogia Geral, posto que é regida por suas normas e princípios (LIZASOÁIN; POLAINO-LORENTE, 2007).

Detendo-se nessa perspectiva, a Pedagogia Hospitalar prioriza o foco em processos de ensino e aprendizagem centrados no aluno e, sob essa ótica, a prática docente pauta-se no estímulo à autonomia e na proposição da elaboração, execução e manutenção dos projetos de vida (MATOS; MUGIATTI, 2009).

O campo da Pedagogia Hospitalar constitui-se em: perspectivas conceituais, enfoque metodológico, boas práticas, formação profissional e pesquisa programada e direcionada às dimensões individuais e grupais.

Para este estudo, elencou-se uma breve análise sobre as Boas Práticas no exercício da Pedagogia Hospitalar. Trata-se de um recorte interessante na gestão do processo educacional de alunos em situação de enfermidade, tendo como ponto de partida a ação e a formação docente. Diante do exposto, a questão que se coloca é: quais as diretrizes que levam a relacionar as melhores práticas em Pedagogia Hospitalar à finalidade de formar cidadãos capazes de se adaptarem às mudanças constantes e de enfrentarem, permanentemente, novos desafios na vida cotidiana?

Certamente, não existe modelo nem fórmula prontos para aplicação nas Classes Hospitalares, tampouco em ambulatórios, domicílios e salas de aula. As Boas Práticas, todavia, dispõem de saberes em construção, sendo a atividade docente uma tarefa inacabada, em constante elaboração e reflexão. Mais que dominar conteúdos, espera-se do docente saberes, competências e habilidades da área da Pedagogia Hospitalar para atender aos desafios da docência na atualidade. Uma breve análise sobre a complexidade dos processos de ensino e de aprendizagem destaca que a prática docente não se reduz à formação básica. Para tanto, é necessário identificar e problematizar outras dimensões e exigir, mais do que nunca, uma formação permanente na área, a qual proporcionará o fomento do desenvolvimento pessoal, profissional e institucional de docentes e das respectivas organizações nas quais exerçam seu trabalho. 
Tomar como referência a sucessiva repetição de ações pedagógicas e educacionais sem que se possa agregar novos conceitos e técnicas para alcançar as singularidades dos alunos e ao mesmo tempo prepará-los para os anseios da sociedade contemporânea não torna a ação docente um exercício do pensamento crítico, dando habilidade para se comunicar e se expressar mediante o sentido de colaboração e de criatividade. Trata-se de um modelo que não se pode considerar como "Boas Práticas" (KIVUNJA, 2018).

Um estudo coordenado pelo grupo de investigação INKLUNI, iniciado em 2018 (GELABERT; BENNASAR, 2019), definiu o conceito de Boas Práticas Inclusivas na área da educação com alunos em situação de enfermidades raras. Trata-se de um trabalho bastante expressivo, que traz sua contribuição ao estabelecer alguns indicadores que permitem reconhecer as Boas Práticas com alunos em situação de enfermidade: ações inovadoras, criativas, duradouras e possíveis de serem sistematizadas e reproduzidas no entorno, fomentando o trabalho colaborativo e inter-relacionado.

Tomando por base os indicadores de Boas Práticas conforme os autores acima mencionados e diante do que foi exposto neste artigo, é possível conceber que estes podem colaborar na determinação de caminhos para enfrentar o desafio da interação entre educador e educando, envolvidos em uma prática sustentada pelos conceitos de educação global e inclusiva. Assim sendo, sob a luz da Pedagogia Hospitalar, as Boas Práticas no fazer pedagógico estão direcionadas para ações que visem oferecer suporte às organizações escolares, a fim de ressignificar o absenteísmo escolar e de estruturar um trabalho com alunos em situação de enfermidade mediante o trabalho em rede cujos atores sejam a família, os profissionais de saúde e educação e demais envolvidos no processo de desenvolvimento do aluno como suporte ao processo de escolarização (MOLINA; ARREDONDO; GONZÁLEZ, 2019).

As Boas Práticas, portanto, dizem respeito a um conjunto de ações que apontam não apenas para a formação continuada do educador, mas também para a integração multiprofissional e interdisciplinar no apoio à aprendizagem, ao desenvolvimento global e à (re)inserção escolar do aluno em 
contínuos tratamentos de saúde, promovendo independência e desenvolvendo positivamente sua autoestima segundo a perspectiva da educação inclusiva.

As ações duradouras compartilhadas entre os interessados demandam um estudo planejado. Entre as possibilidades mencionadas, as pesquisas científicas oferecem um teor de compartilhamento dos trabalhos, segundo padrões previamente estabelecidos e metodologia focada nas necessidades do aluno, suas competências e possibilidades. Dessa forma, será possível comparar ideias de diferentes autores, selecioná-las com base em uma postura crítica. Instigado pela busca constante de informações, o educador também estará em busca de seu crescimento pessoal e profissional.

\section{Considerações finais}

Além do conceito, a integralidade também diz respeito às ações articuladas entre as áreas de saúde e educação, as quais se sincronizam com contextos de pertencimento do aluno, escola e família em uma dimensão dialógica e articulada, permitindo aos profissionais da educação e da saúde se relacionarem com as singularidades de cada indivíduo (MATTOS ${ }^{10}, 2006$ apud HOLANDA; COLLET, 2011).

Assim sendo, a interface educação e saúde como recurso para promover o desenvolvimento de todos em suas dimensões - intelectual, física, afetiva e social - distancia-se da concepção de que o processo de ensino e de aprendizagem esteja restrito ao ambiente escolar, com foco apenas para o conhecimento acadêmico.

Sob essa ótica, nos diferentes ambientes educacionais, o objetivo maior será sempre preparar crianças e adolescentes para conviverem com os desafios da época contemporânea.

\footnotetext{
${ }^{10}$ MATTOS, R. A. Os sentidos da integralidade: algumas reflexões acerca de valores que merecem ser defendidos. R. Pinheiro e R. A. Mattos (orgs.). Os sentidos da integralidade na atenção e no cuidado à saúde. 6. ed. Rio de Janeiro: IMS/UERJ/ABRASCO; 2006. p. 41-66.
} 
Para os que vivem a condição crônica de saúde, a perspectiva da educação integral e inclusiva entrelaça a experiência escolar a fim de promover a inclusão social e comunitária e, dessa forma, a educação se converte em responsabilidade coletiva.

Com a constante menção sobre o avanço da ciência na área pediátrica, as repercussões na qualidade de vida e na longevidade de crianças e adolescentes em situação de DCNTs devem ser acompanhadas de estratégias capazes de transformar as adversidades em novas aprendizagens durante as diferentes etapas da vida. Dessa forma, os cuidados com a doença passam a compor um todo voltado aos cuidados com o doente. Sendo assim, a concepção de saúde agrega ao funcionamento corporal a ideia da saúde em processo, ou seja, em estado de constante construção.

Nesse quadro, a educação figura entre os pré-requisitos básicos considerados como mantenedores da saúde física e mental. A escola como promotora do processo de socialização, desenvolvimento e formação da cidadania, contudo, também deve exercer seu papel social. Ao atender às necessidades singulares de seus educandos em situações adversas de saúde, a escola promove o respeito à diversidade na concepção de formação integral do aluno segundo suas capacidades e talentos, expressos em um ambiente participativo, solidário e acolhedor (MANTOAN, 2006).

Além disso, as singularidades representam a matéria-prima mediante a qual o educador constrói a base para os processos de ensino e de aprendizagem, desde a fase inicial de todas as etapas, permeando o planejamento em si, até o processo de avaliação. Precisamente, é na fase de aprendizagem centrada no aluno que a educação integral e a educação inclusiva se constituem e se fundem. Entre as ações que participam dos processos de ensino e aprendizagem na perspectiva integral e inclusiva, certamente a escola acolhe, ensina e aprende com as singularidades de seus alunos e, ainda, promove, bem como ensina a respeitar, solidarizar, colaborar e conviver com as diferenças de cada um.

O discurso que define uma escola inclusiva passa pela difusão e pelo compromisso de divulgação e prática de ideais inclusivos. Nesse sentido, os 
espaços se constituem com respeito à livre expressão na qual as diferenças possam ser trabalhadas, valorizadas e compreendidas como forma de manifestar a diversidade humana.

Foucault (1981) enfatiza essa questão, apontando que não é suficiente estar dentro para estar incluído. A questão que se apresenta é como ir da diversidade à diferença, como criar dispositivos de convivência ou, ainda, de problematização do ponto de intersecção que põe em tensionamento as dimensões da igualdade e da diferença. Conceber e tratar as pessoas igualmente escondem suas especificidades. No entanto, enfatizar suas diferenças pode excluí-las do mesmo modo. Eis aí a armadilha da inclusão. (MANTOAN, 2012).

\section{Referências}

ALBERTONI, L. C. A inclusão escolar de alunos com doenças crônicas: Professores e gestores dizem que... Curitiba: Appris, 2014.

BARROS, M. B. A., et al. Desigualdades sociais na prevalência de doenças crônicas no Brasil, PNAD-2003. Ciênc. Saúde Coletiva, Rio de Janeiro, v. 11, n. 4, p. 911-926, Dec. 2006. Disponível em:

$<$ http://www.scielo.br/scielo.php?script=sci_arttext\&pid=S1413-

81232006000400014\&lng=en\&nrm=iso >. Acesso em: 4 jul. 2020.

https://doi.org/10.1590/S1413-81232006000400014

BRASIL. Constituição da República Federativa do Brasil. Brasília, 1988. Disponível em:

http://www.planalto.gov.br/ccivil_03/constituicao/constituicao.htm. Acesso em: 9 dez. 2012.

BRASIL. Ministério da Educação. Classe hospitalar e atendimento pedagógico domiciliar: estratégias e orientações. / Secretaria de Educação Especial. Brasília: MEC; SEESP, 2002, 35p.

CÂMARA Municipal de Faro, Divisão de Acção Social, Análise da relação entre o perfil psicossocial do aluno e o abandono escolar. Projecto "Integrar para Educar"- Programa Ser Criança. Ministério do Trabalho e Solidariedade Social, da Câmara Municipal de Faro. Portugal, 2007

CHARLOT, B. Da relação com o saber: elementos para uma teoria. Porto Alegre: Artes Médicas Sul, 2000. Tradução de Bruno Magne. 
CURY, C. R. J. A educação básica como direito. Cad Pesqui, v. 38, n. 134, p. 293-303, maio/ago. 2008. https://doi.org/10.1590/S0100-15742008000200002.

DUARTE, E. D., et al. Cuidado à criança em condição crônica na atenção primária: desafios do modelo de atenção à saúde. Texto Contexto Enferm. Florianópolis, v. 24, n. 4, p. 1009-1017, out-dez. 2015. https://doi.org/10.1590/0104-0707201500003040014.

ENUMO, S. R. F.; FERRAO, E. S.; RIBEIRO, M. P. L. Crianças com dificuldade de aprendizagem e a escola: emoções e saúde em foco. Estud. Psicol. (Campinas), Campinas, v. 23, n. 2, p. 139-149, jun. 2006. Disponível em <http://www.scielo.br/scielo.php?script=sci_arttext\&pid=S0103166X2006000200004\&lng=en\&nrm=iso >. Acesso em: 4 jul. 2020. https://doi.org/10.1590/S0103-166X2006000200004.

FOUCAULT, M. Microfísica do poder (R. Machado, Trad.). Rio de Janeiro: Graal, 1981. (Original publicado em 1979).

GELABERT, S. V.; BENNASAR, F. N. Bones Pràtiques en Entorns Pedagogics. Intervenció i Investigació Educativa i Tecnologica en Pedagogia Hospitalària, n. 3, Maig, 2019.

HERZLICH, C. Health and Illness: A Social-Psychological Analysis. New York: Academic Press, 1973.

HOLANDA, E. R.; COLLET, N. As dificuldades da escolarização da criança com doença crônica no contexto hospitalar. Rev. Esc. Enferm. USP, São Paulo, v. 45, n. 2, p. 381-389, Apr. 2011. Disponível em: http://www.scielo.br/scielo.php?script=sci_arttext\&pid=S008062342011000200012\&lng=en\&nrm=iso. Acesso em: 10 jun. 2020. https://doi.org/10.1590/S0080-62342011000200012.

JERUSALINSKY, J.; LUGON, R. Inclusão sem laudo é um direito da criança! Disponível em: https://emais.estadao.com.br/.../inclusao-sem-laudoe-um-direito-da-crianca. [2016]. Acesso em: 9 ago. 2016.

KIVUNJA, C. Do You Want Your Students To Be Job-ready With 21st Century Skills? Change Pedagogies: A Paradigm Shift From Vygotskyian Social Constructivism To Critical Thinking, Problem Solving And Siemens' Digital Connectivism. In: HARARI, Y. N. 21 lições para o século 21, São Paulo: Companhia das Letras, 2018.

LIZASOÁIN, O.; A POLAINO-LORENTE. La Pedagogía Hospitalaria en Europa: la historia reciente de um movimento pedagógico inovador. Psicothema, v. 4, n. 1, 49-67, 1992. 
LIZASOÁIN, O.; A POLAINO-LORENTE. Reflexiones en torno de la docencia de Educación Especial en el contexto universitario: el reto del Espacio Europeo de Educación Superior. Revista de Ciencias de la Educación, n. 209, p. 101-117, 2007.

MALTA, D. C., et al. Mortalidade por doenças crônicas não transmissíveis no Brasil e suas regiões, 2000 a 2011. Epidemiol. Serv. Saúde, Brasília, v. 23, n. 4, p. 599-608, out-dez 2014. Disponível em <http://scielo.iec.gov.br/scielo.php?script=sci_arttext\&pid=S167949742014000400002\&lng=pt\&nrm=iso >. Acesso em: 7 jul. 2020. https://doi.org/10.5123/S1679-49742014000400002.

MANTOAN, M. T. E. Escolas dos diferentes ou escolas das diferenças? ComCiência, Campinas, n. 135, fev. 2012. Disponível em $<$ http://comciencia.scielo.br/scielo.php?script=sci arttext\&pid=S151976542012000100009\&lng=pt\&nrm=iso >. Acesso em: 4 jul. 2020.

MANTOAN, M. T. E. Inclusão Escolar. O que é? Por quê? Como fazer? 2. ed. São Paulo: Moderna, 2006.

MATOS, E. L. M.; MUGIATTI, M. M. T. F Pedagogia Hospitalar: a humanização integrando educação e saúde. 4 ed. Petrópolis, RJ: Vozes, 2009.

MOLINA, M. C.; VIOLANT, V.; LIZASOÁIN, O. Educación, salud y enfermedad. Las bases de la Pedagogía Hospitalaria. En: BOBADILLA, A., et al. La Pedagogía Hospitalaria Hoy. Análisis de las Políticas, los ámbitos y la formación de profesionales. Santiago de Chile: Santillana, p. 14-17, 2013.

MOLINA, M. C.; ARREDONDO, T.; GONZÁLEZ, J. Buenas prácticas e innovación en el contexto de la educación inclusiva. In: ___. (edit.). Buenas prácticas e innovación en pedagogía hospitalaria. La atención hospitalaria y domiciliaria. Barcelona: Octaedro, 2019.

MOREIRA; M. C. N.; GOMES, R.; SA, M. R. C. Doenças crônicas em crianças e adolescentes: uma revisão bibliográfica. Ciênc. Saúde Coletiva, Rio de Janeiro, v. 19, n. 7, p. 2083-2094, jul. 2014. Disponível em: <http://www.scielo.br/scielo.php?script=sci_arttext\&pid=S141381232014000702083\&lng=en\&nrm=iso >. Acesso em 4 jul. 2020. https://doi.org/10.1590/1413-81232014197.20122013.

NESCON - Núcleo de Educação em Saúde Coletiva. O Conceito de Condições de Saúde. Organização Panamericana de Saúde. 2012.

NOGUEIRA, K. T. O adolescente com doença crônica. PRONAP - Programa Nacional de Educação Continuada em Pediatria, v. 19, p, 44-53, 2016. 
OLIVEIRA, A. F. et al. Global burden of disease attributable to diabetes mellitus. Cad Saúde Pública, Rio de Janeiro, v. 25, n. 6, p. 1234-44, jun. 2009. https://doi.org/10.1590/S0102-311X2009000600006.

ORGANIZAÇÃO MUNDIAL DA SAÚDE (OMS). Cuidados inovadores para condições crônicas: componentes estruturais de ação: relatório mundial. Brasília: OMS; 2003.

SALDANHA, G. M. M. M.; SIMÕES, R. R. Educação escolar hospitalar: o que mostram as pesquisas? Rev. Bras. Educ. Espec., Marília, v. 19, n. 3, p. 447-464, Sept. 2013. Disponível em:

http://www.scielo.br/scielo.php?script=sci_arttext\&pid=S1413-

65382013000300010\&lng=en\&nrm=iso. Acesso em: 20 jun. 2020.

https://doi.org/10.1590/S1413-65382013000300010.

SALDARRÍAGA, J. F.; MARTÍNEZ, E. Factores asociados al ausentismo laboral por causa médica en una institución de educación superior. Rev. Fac. Nac. Salud Pública [online], Medellin, v. 25, n. 1, p. 32-39, 2007.

SILVA FILHO, R. B.; ARAÚJO, R. M. L. Evasão e abandono escolar na educação básica no Brasil: fatores, causas e possíveis consequências.

Educação por Escrito, v. 8, n. 1, p. 35-48, 2011. https://doi.org/10.15448/2179-8435.2017.1.24527.

VASCONCELLOS, S. S.; MATTOS, C. L. G. O absenteísmo escolar e sua regulamentação. In MATTOS, C. L. G.; CASTRO, P. A. (orgs). Etnografia e educação: conceitos e usos [online]. Campina Grande: EDUEPB, 2011, pp. 271-296. Disponível em: http://books.scielo.org. Acesso em: 3 jul. 2020.

VIEIRA, M. A.; LIMA, R. A. G. Crianças e Adolescentes com Doenças Crônicas: Convivendo com Mudanças. Rev Latino-Am Enfermagem [online], v. 10, n. 4, p. 552-560, jul-ago, 2002. Disponível em:

https://www.scielo.br/scielo.php?pid=S0104$11692002000400013 \&$ script=sci_abstract\&tlng=pt. Acesso em: 3 jul. 2020. https://doi.org/10.1590/S0104-11692002000400013.

Recebido em abril de 2020. Aprovado em dezembro de 2020. 